Objectives: To evaluate the validity and responsiveness of the 8-item Neuro-QoL UEF in RA. We hypothesized scores would be strongly $(r>.70)$ associated with MHAQ, MD-HAQ, and PROMIS PF, moderately ( $r=.4$ to .7) to symptoms, disease activity, and QoL indicators, and be responsive to change in disease activity and PF.

Methods: Data were from the 0 and 6-month visits of adults with early RA (sx $<1$ yr) enrolled in the Canadian Early Arthritis Cohort, a prospective real-world study at 16 sites across Canada. Participants completed the Neuro-QoL UEF, MHAQ, MDHAQ, PROMIS-29, and PT Global at each visit. Rheumatologists recorded joint counts and MD Global. To evaluate content validity, we examined descriptive statistics across CDAl disease activity levels, and Pearson correlations between the Neuro-QOL UEF, legacy measures, CRP \& ESR. Responsiveness was assessed by correlating change scores from visits 0-6 between Neuro-QoL UEF disease activity and legacy PF scores.

Results: The 262 participants were mostly white $(83 \%)$ women $(71 \%)$ with a mean (SD) age of 55 (13). Summary statistics at 6-months are shown in Table 1. Neuro-QOL UEF was moderately-strongly correlated with MHAQ, MDHAQ, PROMIS-PF ( $|\mathrm{r}|=.63-.75)$ and moderately correlated with pain and stiffness, ( $|r|=.59,-.64)$, and CDAI, SDAI, PT\&MD Global, TJ \& SJ ( $|r|=.39-.58)$. Neuro-QOL UEF was moderately correlated with PROMIS QoL domains Pain, Fatigue, Anxiety, Depression, Sleep \& Participation ( $|r|=.39-.60)$

Table 1. Summary statistics of physical function and RA disease activity indices at 6 months.

\begin{tabular}{lcccccc}
\hline & Mean & SD & Mdn & $\mathbf{2 5 \%}$ & $\mathbf{7 5 \%}$ & (Min, Max) \\
\hline Physical Function & & & & & & \\
\hline Neuro-Qol UEF & 46.5 & 9.7 & 53.8 & 37.5 & 53.8 & $(21.8,53.8)$ \\
MHAQ (0-3) & 0.29 & 0.43 & 0.13 & 0.00 & 0.38 & $(0.00,2.25)$ \\
MD-HAQ (0-10) & 1.39 & 1.64 & 0.70 & 0.00 & 2.00 & $(0.00,8.00)$ \\
PROMIS-PF & 46.4 & 8.5 & 46.2 & 39.5 & 56.0 & $(23.3,56.0)$ \\
RA Disease Activity & & & & & & \\
CDAl & 9.3 & 9.9 & 6.0 & 3.0 & 13.0 & $(0.0,56.0)$ \\
SDAI & 10.7 & 10.9 & 6.8 & 3.1 & 15.2 & $(0.0,57.0)$ \\
Patient Global & 3.0 & 2.5 & 3 & 1 & 5 & $(0,10)$ \\
MD Global & 1.8 & 2.2 & 1 & 0 & 3 & $(0,9)$ \\
Swollen Joints (28) & 2.1 & 3.7 & 0 & 0 & 2 & $(0,20)$ \\
Tender Joints (28) & 2.4 & 3.9 & 1 & 0 & 3 & $(0,24)$ \\
\hline
\end{tabular}

Neuro-QOL scores decreased in a dose-response manner across worsening CDA DA states reflecting increasing impairment (Table 2). Persons with HDA reported the highest disability, scoring nearly 0.5 SD lower on the Neuro-QoL UEF than PROMIS PF. Change from baseline to 6 months in Neuro-QoL UEF was moderately correlated with changes in PROMIS PF, MHAQ, PT Global, and CDAI $(|r|=.44-.65)$. The mean change and range from 0-6 months in Neuro-QoL was significantly larger than in PROMIS (8.9 [95\% Cl 7.5, 10.4] vs. 5.4 [95\% Cl 4.4, 6.4])(see Figure).

Table 2. Mean scores $(95 \% \mathrm{Cl})$ at 6 months by CDAl level.

\begin{tabular}{lcccc}
\hline & REM & LDA & MDA & HAD \\
\hline NeuroQol UEF & $52.8(51.8,53.7)$ & $48.1(46.6,49.7)$ & $42.0(39.4,44.6)$ & $33.8(30.5,37.1)$ \\
MHAQ (0-3) & $0.05(0.02,0.09)$ & $0.19(0.14,0.24)$ & $0.45(0.34,0.57)$ & $0.90(0.63,1.17)$ \\
MD-HAQ (0-10) & $0.31(0.17,0.46)$ & $1.11(0.90,1.32)$ & $2.15(1.71,2.59)$ & $3.56(2.56,4.56)$ \\
PROMIS-PF & $52.8(51.4,54.2)$ & $46.8(45.3,48.2)$ & $42.3(40.4,44.2)$ & $38.0(34.4,41.6)$
\end{tabular}

Conclusion: Clinicians, researchers, and patients benefit from practical self-report tools that reliably and precisely monitor hand function in RA. Results offer initial evidence of validity and responsiveness and support use of Neuro-QoL UEF to self-assess inflammatory activity in the hands and day-to-day experiences of living with RA.

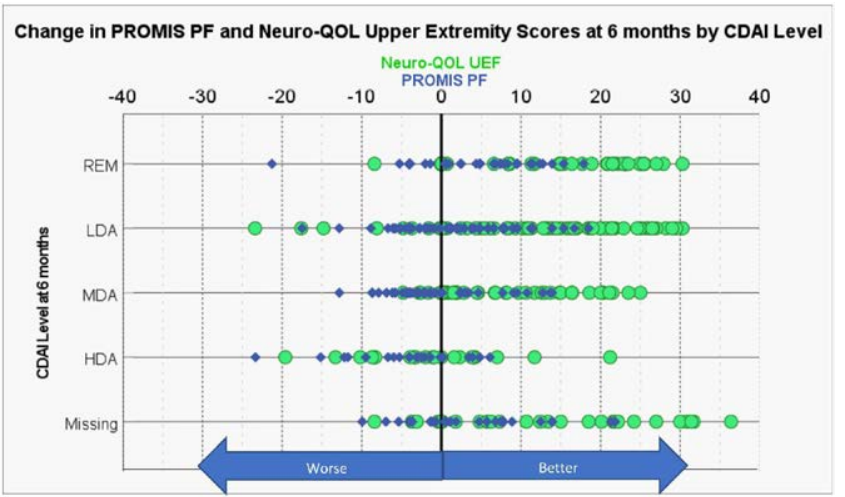

Acknowledgements: The CATCH study was designed and implemented by the investigators and financially supported through unrestricted research grants from: Amgen and Pfizer Canada - Founding sponsors since January 2007; AbbVie Corporation and Hoffmann-LaRoche since 2011; Medexus Inc. since 2013; Merck Canada since 2017, Sandoz Canada, Biopharmaceuticals since 2019, Gilead Sciences Canada since 2020 and Fresenius Kabi Canada Ltd. since 2021. Previously funded by Janssen Biotech from 2011-2016, UCB Canada and Bristol-Myers Squibb Canada from 2011-2018, Sanofi Genzyme from 2016-2017, and Eli Lilly Canada from 2016-2020.

Disclosure of Interests: None declared

DOI: 10.1136/annrheumdis-2021-eular.3259

\section{OP0263-HPR THE ROLE OF PHYSICAL EXERCISES IN REDUCING CHRONIC FATIGUE IN PATIENTS WITH RHEUMATOID ARTHRITIS}

A. Aleksandrov ${ }^{1,2}$, M. Nikitin ${ }^{3}, \underline{\text { V. Aleksandrov }}{ }^{1,2}$, N. Aleksandrova ${ }^{1} .{ }^{1}$ Federal State Budgetary Institution «Research Institute of Clinical and Experimental Rheumatology named after A.B. Zborovsky", Department of Functional Research Method, Volgograd, Russian Federation; ${ }^{2}$ Volgograd State Medical University, Department of Hospital Therapy, Volgograd, Russian Federation; ${ }^{3}$ FSB Institution "National Medical Research Center for Rehabilitation and Balneology" of the Ministry of Health of the Russian Federation, SanatoriumResort Complex "Vulan"- Scientific and Clinical Branch, Gelendzhik, Russian Federation

Background: Physical activity is an important non-pharmacological intervention that has a combination of biological, physical and psycho-social benefits and can positively influence chronic fatigue in patients with rheumatoid arthritis (RA) $[1,2,3]$.

Objectives: Evaluation of the effectiveness of the use of aerobic exercise (walking) to reduce fatigue in RA patients.

Methods: The study included 111 women with RA (mean age $54.4 \pm 11.03$ years old, mean duration of illness - $11.9 \pm 9.3$ years old). The DAS28-ESR indicator in RA patients was 2.84 [2.32; 3.05] points: low disease activity was diagnosed in $61.3 \%$ of patients, and remission in $38.7 \%$. The average level of fatigue according to the VAS screening scale was $71.6 \pm 8.93$ points. Fatigue was assessed using the Bristol Rheumatoid Arthritis Fatigue Numerical Rating Scale (BRAF-NRS V2). To assess the patient's tolerance to physical activity, a 6-minute walking distance (6MWD) test was used. A walking test at 50 meters was used to assess the functional state of patients in dynamics. The rehabilitation program (RP) of patients (for 21 days) included morning hygienic gymnastics, dosed walking (daily, duration 30-60 minutes) and walking in the air up to 3-3.5 hours a day. Vigorous movements "through pain" were contraindicated.

Results: No association was found between the duration of RA and all of the used numerical fatigue scales ( $p>0.05)$, but there was a weak positive relationship between VAS and NRS-overcoming with age $(r=0.21$ and $r=0.28)$. An association between DAS28-ESR and numerical fatigue scales VAS $(r=0.21)$, NRS effect $(r=0.25)$ and NRS - overcoming $(r=0.24)$ was found, despite the fact that this study did not include patients with moderate and high RA activity. There was a significant correlation between the walking time and the number of steps during the 50 -meter test $(r=0.6, p<0.001)$, as well as an association between the fatigue and the walking time $(r=0.33, p=0.001$ for VAS and $r=$ $0.41, p<0.001$ for NRS-severity) and the number of steps $(r=0.39, p<0.001$ fo VAS; $r=0.47, p<0.001$ for NRS-severity; $r=0.44, p<0.001$ for NRS-bridging)

Table 1. Dynamics of fatigue levels and physical indicators in RA patients

\begin{tabular}{lccc}
\hline & Before RP & In the end of RP & p \\
\hline VAS fatigue level & $71,2 \pm 9,08(71,5 ; 64-78)$ & $70,4 \pm 9,15(70 ; 64-78)$ & $p>0,05$ \\
BRAF-NRS: severity & $6,83 \pm 1,21(7 ; 6-8)$ & $6,51 \pm 1,18(7 ; 6-7)$ & $\mathrm{p}<0,01$ \\
BRAF-NRS: effect & $6,24 \pm 1,07(5 ; 4-6)$ & $5,95 \pm 1,08(6 ; 5-7)$ & $\mathrm{p}<0,05$ \\
BRAF-NRS: overcoming & $5,0 \pm 1,7(7 ; 6-8)$ & $7,76 \pm 1,37(5 ; 4-5)$ & $\mathrm{p}>0,05$ \\
50 meter test, number of steps & $79,3 \pm 8,64(78 ; 73-84)$ & $78,91 \pm 8,15(78 ; 73-83) \mathrm{p}>0,05$ \\
50-meter test, walking time, & $56,7 \pm 8,72(57 ; 50-63)$ & $55,9 \pm 8,59(56 ; 51-60)$ & $\mathrm{p}=0,01$ \\
$\quad$ seconds & &
\end{tabular}

* The data are presented as mean \pm standard deviation (median; interquartile range)After the completion of RP (Table), RA patients showed a significant reduction in the aspects of fatigue according to the NRS-severity $(Z=2.98, p=0.003)$ and NRS-effect $(Z=2.08, p=0.037)$ scales. There was also a decrease in the time spent by patients performing the $50 \mathrm{~m}$ walking test $(t=2.63, p=0.01)$, but the total number of steps did not change $(t=1.44, p=0.154)$. Fatigue and pain are important barriers to physical activity, but it is severe fatigue that reduces physical activity in patients with RA [4]. At the same time, physical activity itself can become a factor in reducing fatigue [5], including by reducing the activity of the disease [6].

Conclusion: The severity of fatigue in RA patients can be reduced by actively using non-pharmacological treatment strategies. Walking is a simple and effective solution to increase physical activity and it has a significant effect on fatigue in RA. 


\section{REFERENCES:}

[1] Rongen-van Dartel SA et al. Arthritis Care Res (Hoboken). 2015;67:1054-1062.

[2] Brosseau L et al. PLoS One. 2014;9(5):e95369.

[3] Cherkashina IV et al. Vopr Kurortol Fizioter Lech Fiz Kult. 2016;93(2):13-16.

[4] Loppenthin K et al. Rheumatol Int. 2015;35:1655-1664.

[5] Cramp F et al. Cochrane Database Syst Rev. 2013;8:CD008322.

[6] Sveaas SH et al. Br J Sports Med. 2017;51:1065-1072.

Disclosure of Interests: None declared

DOI: 10.1136/annrheumdis-2021-eular.3211

\section{OP0264-HPR "I LITERALLY CONVINCED MYSELF I WAS GOING TO CATCH IT AND DIE": LIVED EXPERIENCES OF THE COVID-19 PANDEMIC BY PEOPLE WITH RHEUMATIC DISEASES FROM FOUR EUROPEAN COUNTRIES}

R. J. O. Ferreira ${ }^{1,2}$, C. Costa $^{3}$, A. Marques ${ }^{1,2,4}$, A. J. Barata Cavaleiro ${ }^{2,4}$, S. Makri ${ }^{5}$, K. Parperis ${ }^{6}$, S. Psarelis ${ }^{7}$, R. Williams ${ }^{8}$, G. E. Fragoulis ${ }^{9}$, H. Lempp ${ }^{8}$, E. Nikiphorou $8,10 .{ }^{1}$ Centro Hospitalar e Universitário de Coimbra, Rheumatology, Coimbra, Portugal; ${ }^{2}$ Escola Superior de Enfermagem de Coimbra, Health Sciences Research Unit: Nursing (UICISA: E), Coimbra, Portugal; ${ }^{3}$ Centro Hospitalar e Universitário de Coimbra, Ortophedics, Coimbra, Portugal; ${ }^{4}$ Escola Superior de Enfermagem de Coimbra, UCP Elderly Nursing, Coimbra, Portugal; ${ }^{5}$ Cyprus League Against Rheumatism, Board, Nicosia, Cyprus; ${ }^{6}$ University of Cyprus Medical School, Rheumatology, Nicosia, Cyprus; ${ }^{7}$ Nicosia General Hospital, Rheumatology, Nicosia, Cyprus; ${ }^{8}$ King's College London, Centre for Rheumatic Diseases, London, United Kingdom; ${ }^{9}$ Laiko Hospital, University of Athens, First Department of Internal Medicine, Athens, Greece; ${ }^{10} \mathrm{King}$ 's College Hospital, Rheumatology, London, United Kingdom

Background: The COVID-19 pandemic has resulted in unforeseen challenges for humanity, taking a significant toll, especially the immune-suppressed individuals. In this regard, the health and general well-being of people with rheumatic diseases, the great majority users of immunosuppressives, have been at stake. Objectives: To explore the impact of the COVID-19 pandemic on people with rheumatic diseases on immunosuppression during the first wave, concerning a) (self-)management of their disease; b) interaction with the health care team; c) emotional well-being and d) overall health.

Methods: A qualitative study was conducted following a phenomenological approach. Adults ( $>18$ years) with a rheumatic disease from four European countries (Cyprus, England, Greece, Portugal). Patients were recruited through patient's associations and social media and were invited to participate in semi-structured, audio-recorded interview or focus groups, between July August 2020. Following a pilot study the information provided was transcribed verbatim, anonymized and translated into English where necessary. An inductive approach was adopted to carry out a thematic framework analysis with the assistance of ATLAS.ti to identify key themes and subthemes. Data validation strategies were employed, and Ethical approval and informed consent were obtained. Results: Participants were 24 patients (21 women, age range 33 to 74 years) divided by 7 focus-groups and 1 individual interview. Most frequent diagnoses were rheumatoid arthritis $(n=7)$, lupus $(n=4)$, juvenile idiopathic arthritis $(n=3)$. Three key themes with 3-7 subthemes were identified within the analytical framework, centred around the impact of the Covid-19 on patients' lives (Figure 1): i) individual person (e.g. fear for myself and family, social isolation and lack of personal freedom, more time with family) ii) health settings (e.g. (un)clear information about risks of contamination, fear or risk of shortages of medication, remote consultations), and iii) work and community (e.g. persistent stress due to mass media exposure, lack of awareness by others about patients' rheumatic disease and its disclosure, hope and suspicion about new vaccine development: "I hear that they will ask vulnerable groups to have the vaccine first (...) Why is that? we will be again the innocent victims"). Findings were similar across countries, except for spirituality (i.e. the pandemic as "the hand of God"), a coping subtheme particular to Portugal. These main themes resonated well with the social ecological model and Walsh's Family Resilience Process [1,2].
Figure 1. Lived experiences of the Covid-19 pandemic by people with rheumatic diseases

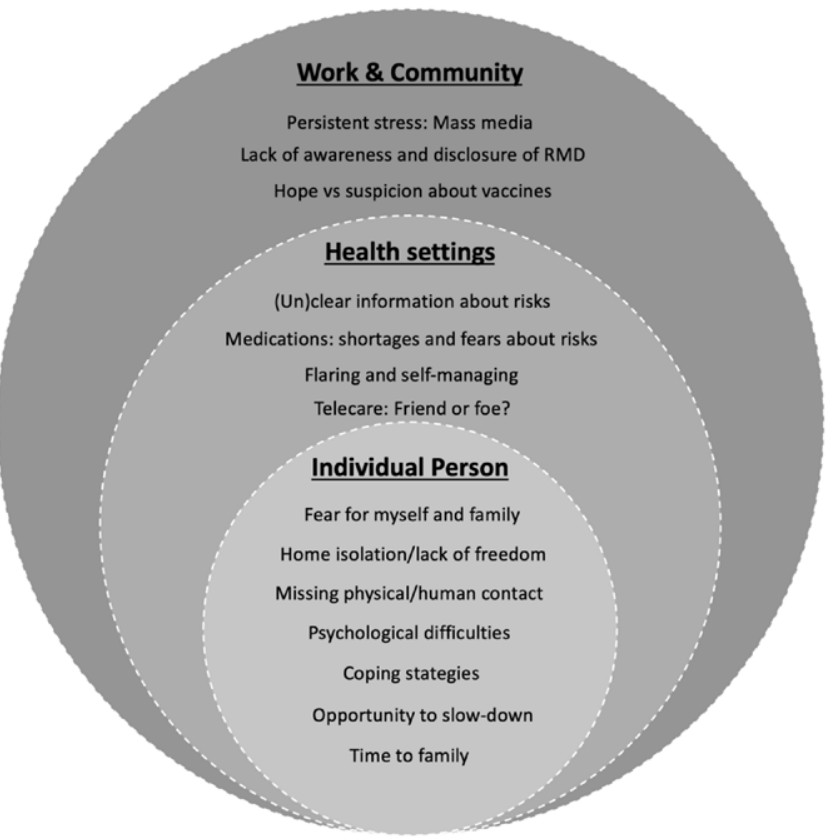

Conclusion: When experiencing a significant life-event people require some time to process the different lived experiences. This study provides insights on how patients from four countries coped with the new challenges. Such insights are invaluable for health care providers and policy makers, in guiding more meaningful support tailored to individual needs, especially at times of crisis. The study highlights the impact of COVID-19 on the lives of people with rheumatic disease. A follow-up study is currently underway to examine the effect of subsequent waves of the pandemic.

REFERENCES:

[1] Golden SD, Earp JA. Social ecological approaches to individuals and their contexts: twenty years of health education \& behavior health promotion interventions. Health Educ Behav. 2012;39(3):364-72. doi: 10.1177/1090198111418634.

[2] Walsh F. Family resilience: a framework for clinical practice. Fam Process. 2003;42(1):1-18. doi: 10.1111/j.1545-5300.2003.00001.

Acknowledgements: We thank the participants of this study.

Disclosure of Interests: None declared

DOI: 10.1136/annrheumdis-2021-eular.1586

\section{OP0265-HPR IMPACT OF COVID-19 PANDEMIC ON RHEUMATOLOGY PATIENTS IN NORTHERN IRELAND - A WEB BASED CROSS-SECTIONAL SURVEY}

P. McKee ${ }^{1}$, A. Irvine ${ }^{1}$, C. Riddell ${ }^{1}$, E. Ball ${ }^{1}{ }^{1}$ Musgrave Park Hospital, Rheumatology, Belfast, United Kingdom

Background: Concern for the susceptibility of rheumatology patients to severe COVID-19 illness has been raised since the start of the pandemic. Rheumatic disease and their immunosuppressant therapies placed many patients into the 'clinically extremely vulnerable' group when the UK's shielding guidance commenced on 23 March 2020. The impact of DMARDs/glucocorticoids/biologics on COVID-19 remains under investigation ${ }^{1}$. A recent study suggested caution may be required with rituximab and sulfasalazine in COVID-19 patients ${ }^{2}$. 